\title{
Letters
}

To the Editor:

It was with some surprise that I opened the July 1996 issue of CERL to find an article by Barbara Via entitled "Publishing in the Journal Literature of Library and Information Science: A Survey of Manuscript Review Processes and Acceptance." In that article Via states that she was updating a previous study done by me (which, in turn, built upon a study by Phyllis Van Orden and Daniel $\mathrm{O}^{\prime}$ Connor). The surprise I experienced was due to the fact that I have just conducted a study building upon my previous work and, at the time the CERL issue was received, my paper was being reviewed for publication by the editors of Library Journal. I should state that I do not dispute Via's findings or method. What I do have a problem with, however, is the apparent renunciation of research protocols and the absence of professional courtesy that this published paper represents.

Several years ago I was intrigued by the survey of Van Orden and O'Connor and thought that updated information could be of interest to prospective authors. At that time I contacted the authors and asked if they intended to conduct a follow-up study. When they informed me that they had no such plans I sent a questionnaire to editors. I received no such query from Via and, since I had assumed that I had something of an intellectual claim staked, planned to undertake the follow-up. The work I have done, however, is rendered redundant by the appearance of the article.

Library education probably has to accept some responsibility for less than adequate preparation of librarians as researchers. We educators should be more diligent in our efforts to acculturate students into the society of researchers, and its attendant responsibilities. Individuals, though, need to accept the responsibility that accompanies publication. This letter may sound, to some, like sour grapes, but the breach of courtesy that the article represents transcends the sensibilities of

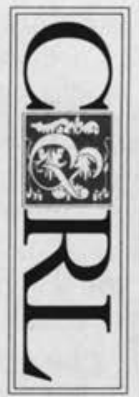
any one individual. I hope that this incident can serve to increase an awareness of protocol and that such an experience can be avoided in the future.

John M. Budd

University of Missouri-Columbia

\section{Author's Response:}

In response to Professor Budd's letter, I am sorry if he feels that I was professionally discourteous and I regret any inconvenience that the publishing of my article may have caused him in pursuing his own research.

\section{Barbara Via \\ University of Albany, SUNY}

To the Editor:

In the July 1996 issue of CERL, we read an article by Barbara J. Via in which our recently published monograph was referred to in this manner:

In a recent monograph, Guide to Publishing Opportunities for Librarians, Carol F. Schroeder and Gloria Roberson define a refereed journal as "one in which submitted manuscripts are evaluated by an independent expert or a panel of experts. The reviewers evaluating the manuscript may be members of the journals' editorial board, or external reviewers, or a combination of both" The list of refereed journals provided in the book includes several titles that did not include on the survey reported here that they employ a referee process in their review of manu- 
scripts. These titles included: The Bottom Line, Collection Building, and The International Journal of Micrographics and Optical Technology.

We wish to advise you of the following errors, and request that you consider publishing a correction.

1) The Bottom Line is not refereed and we never indicated in our book that it was a refereed journal.

2) The International Journal of Micrographics and Optical Techcnology is not included in our book, and there seems to be no explanation for Via's reference to it.

3) Collection Building is refereed. We endeavored to support the veracity of our survey by consulting the journal itself. In "Guidelines for Contributors" (Collection Building, Vol. 14, No. 1, 1955) it states that "other than solicited articles, all manuscripts will be blind-refereed prior to publication." Further, in "Guidelines for Contributors" (Vol. 15, No. 3, 1966) it states that "each paper submitted to $\mathrm{Col}$ lection Building is ... reviewed by the editor for general stability." If found to be suitable, "two reviewers are selected and a blind review process takes place."

As conscientious librarians, we feel that the explanations presented here clearly demonstrate that Via's statement concerning Guide to Publishing Opportunities as "misinformation on whether given journals are refereed or not abounds" does not apply.

Thank you in advance for your attention to this matter.

\section{Carol Schroeder \\ Gloria Roberson Adelphi University}

Author's Response:

The above letter from Carol $F$. Schroeder and Gloria Roberson points out errors in my article. Schroeder and Roberson are indeed due an apology for the editing error I inadvertently allowed to appear in the published article. It ap- pears, from my rereading of the article, that somehow, in one of numerous rewrites, I repeated titles of journals which Molly Skeen listed as refereed in her book (which I also cite), in my reference to Schroeder and Roberson's book. The titles that I intended to cite from Schroeder and Roberson's list of refereed journals are: The Acquisitions Librarian, Public Library Quarterly, The Reference Librarian, and Resource Sharing and Information Networks. Both the Acquisitions Librarian and the Reference Librarian, edited by Bill Katz, solicit all manuscripts. The editor of Public Library Quarterly indicated on my survey that he alone decided on acceptance. The editor of Resource Sharing and Information Networks indicated that he alone reviews and decides on manuscripts, except in cases where the subject of the manuscript is outside his areas of expertise.

While I regret the errors in my article, I do stand by my assertion that Schroeder and Roberson's book, and the others I cited, do not provide their readers with reliable information as to which journals are refereed. Schroeder and Roberson define a refereed journal as being "one in which submitted manuscripts are evaluated by an independent expert or a panel of experts. The reviewers evaluating the manuscript may be members of the journals' editorial board, or external reviewers, or a combination of both." By this definition, any journal, except those wherein the editor and/or the editorial staff alone review and make the acceptance decision, would qualify as refereed. The list of refereed journals provided by Schroeder and Roberson, in an otherwise excellent author's guide, does not help to clarify for the prospective author which journals are truly and consistently refereed.

The differing answers provided by journal editors to Schroeder and Roberson's survey and my survey provide further evidence that for the field of library and information science the concept of a ref- 
ereed journal is not well defined, nor consistently applied.

Barbara J. Via

University of Albany, SUNY

\section{To the Editor:}

In the July 1996 issue of CERL, Barbara J. Via made several statements with which I, most respectfully, disagree.

In several places in her article, Via concludes that the more articles that are published, the lower the quality of the average article. She quotes Eric Moon: "perhaps the most constructive single thing that could be accomplished would be to persuade at least one in three publishers of a library periodical to cease publication." Later she states, "most certainly spreads the limited number of quality articles among diffuse journals."

Via presumes that there is some magic number of high-quality articles written each year. Is that number equal to the precise number that will fit into ten journals or twenty-two journals or thirty-seven journals. Everyone knows of fine articles refused by one journal and accepted by another. Where do these articles fit in the magic number theory?

Do we have any genuine research on the relative quality of articles in various journals? Why doesn't someone gather a group of referees to blind review a random selection of articles in several journals? I believe several prestigious journals are running on past glory.

Is ours a richer profession because Wilson Library Bulletin is gone? Will American Libraries and Library Journal im- prove because Wilson is gone? Are we better off because we do not have Mary Jackson's monthly interlibrary loan column to read?

Journals serve another purpose. When I announced the first issue of the Journal of Interlibrary Loan, Document Delivery and Information Supply, I received several letters thanking me. The letter writers felt that interlibrary loan was not really a field of librarianship unless it had a journal. A journal certifies and legitimizes an area of expertise.

It may be true that the scope of some of the articles in smaller field journals are narrow. I do not read journals about music librarianship. They are out of my area, but how often will someone write an article about music librarianship that has enough general interest to be published in CERL?

Via does not seem to understand that the economics of publishing journals has changed. Formerly, journal publishing was so expensive that only large print runs were economical. Therefore, only a few journals in each subject were profitable. As the price of short print runs has declined, the economics of journals addressed to smaller audiences has become more practical.

The future economics of journal publishing probably mean that even more specialized journals will emerge.

My advice to Via is to vote with your checkbook. Do not subscribe.

Lester R. Morris

Editor, Journal of Interlibrary, Loan, Document Delivery \& Information Supply 


\title{
A CURE FOR AIDS WILL HAVE TO GET PAST THE FDA.
}

\author{
The World Health Organization.
}

And the Centers for Disease Control.

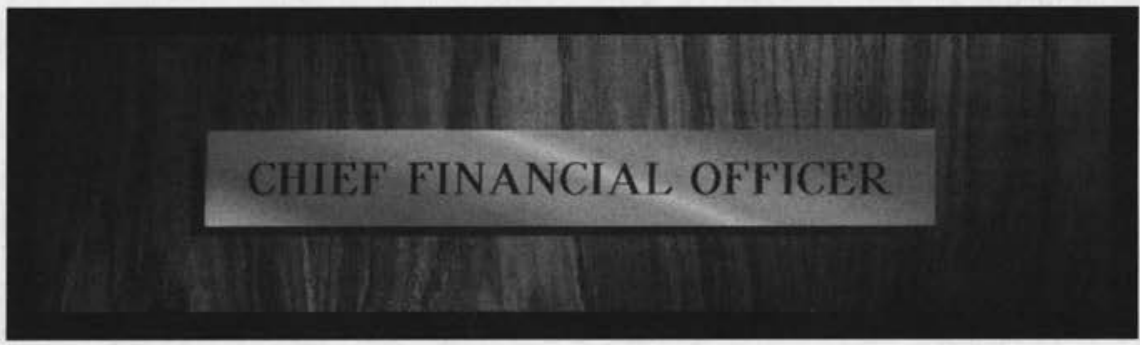

\section{BUT FIRST IT'S GOT TO GET PAST SOMEONE ELSE.}

As much as we'd like to think that profit plays no part in medical breakthroughs, the biotechnology and health care industries are businesses - with justifiable needs to pursue healthy bottom lines. But what if business chose to save money over lives?

You can explore all sides of this and other critical public and social policy issues through PAIS International. PAIS gives you instant access to an index of some 400,000 hard-to-find articles, books, government documents,

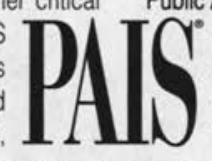

statistical directories and more. It references literature published around the globe. And now it's even available on leased tape.

So if you're looking for information, go through the right channel. Use PAIS.

Public Affairs Information Service, Inc.

NO ONE LOOKS AT THE WORLD LIKE PAIS

\section{Now AVAILABLE: PAIS SELECT, OUR NEW FULL-TEXT CD-ROM.} CALL TODAY TO TAKE ADVANTAGE OF INTRODUCTORY PRICING.

On CD-ROM: PAIS ON CD-ROM - PAIS SELECT FULL-TEXT + PAIS INTERNATIONAL ON SILVERPLATTEA + PAIS/EBSCO CD PAIS INTERNATIONAL ON OVID In Print: PAIS INTERNATIONAL IN PAINT O Online through: DATASTAR - DIALOG
EBSCOHOST - INFOTRAC SEARCHBANK. OCLC. OVID - RLG On Magnetic Tape: CONTACT PAIS FOR INFORMATION 